\title{
Correspondence
}

\section{Drugs, information and influence}

Sir: The interesting paper by Babor et al (Psychiatric Bulletin, July 1996, 20, 406-409) tentatively offers reassurance about the influence of advertising, but the need for caution remains.

Drug companies may spend over a million pounds on marketing a new product and it therefore seems surprising that doctors in this study felt almost immune from the influence of advertisements in their prescribing. As with most sophisticated consumers, doctors are unlikely to respond to direct product-orientated advertising. Drug companies are highly sophisticated advertisers and are aware of such consumer characteristics. They will plan advertising, within an overall marketing strategy, to fulfil a number of different functions including: making an impact. creating product awareness, changing perception, reinforcing attitudes and long-term brand awareness (D'Souza, 1989). They will seek to target specific doctors with the greatest influence, for example consultants who may be involved in developing hospital formularies, which may then become secondary advertisements.

It is then tempting to view advertisements as manipulating the consumer into making inappropriate choices and therefore undesirable. However, psychotropic advertisements are more complicated and have been shown to serve an orienting and therapeutic function for physicians. mirroring and supporting professional identity (Neill, 1989). Advertisements are also perceived as helpful in allowing doctors to keep up with new developments (Crown, 1996).

The subtlety and interactive nature of the advertiser's message needs to be fully appreciated and a failure to consistently demonstrate linear causal relationships does not exclude a powerful influence.

Crown. S. (1996) Advertising in psychopharmacology. Psychiatric Bulletin, 20, 370.

D'SouzA. S. (1989) The roles of advertising. In How to Plan Advertising (ed. D. Cowley). pp 13-40. London: Cassell Education Limited.

NEIL. J. R. (1989) A social history of psychotropic drug advertisements. Social Science and Medicine, 28, 333-338.

TIM MORRIS, Wirral Community NHS Trust, Adcote House, Columbia Road, Wirral L63 6TU

Sir: I write in response to the letter from Sidney Crown, Psychiatric Bulletin (June 1996, 20, 370), concerning the booklet Highlights-Managing Depression with the Whole Patient in Mind prepared by Lundbeck Limited. As a post-conference summary, this document was intended to provide notification of the meeting's content and findings in abbreviated form, ahead of the full publication, which has now been published (Leonard \& Montgomery, 1996).

Much of the meeting was based around published data, however, the forum was used to present new data, including a comprehensive review of the safety and tolerability of citalopram.

The provision of data in summarised form in advance of full paper publication is well established. As this meeting used innovative technology to record the views of more than 350 UK psychiatrists on topical issues in the management of depression, we felt the results would be of particular interest to the wider community of psychiatrists. I should also point out that all the speakers concerned had an opportunity to review the summary of their presentation before distribution. I hope this clears up any misunderstanding concerning the objective of this booklet.

LEONARD, B. \& MONTGOMERY, S. (eds) (1996) Managing Depression with the Whole Patient in Mind. Papers presented at an interactive focus conference, 2 and 3 June 1995. International Clinical Psychopharmacology. 11 (Suppl 1), 5-50.

CHRIS MULDOON, Medical Director, Lundbeck Limited, Caldecotte, Multon Keynes MK7 8LF

\section{Child mental health}

Sir: I feel I must object in the strongest terms at both the style and content of Dr Bartlet's article "School pressures and child mental health in Afro-Asian countries" (Psychiatric Bulletin, 1996. 20, 301-303). While I agree that poor resources and poverty have many consequences in both education and children's mental health, I believe Dr Bartlet has not only misunderstood these dynamics but in addition the portrait painted by this article is racist and offensive.

My first objection is to the category 'Afro-Asian'. Dr Bartlet jumps around these two vast and diverse continents citing examples from many countries. These examples are then compared (unfavourably) to the West. Economic, cultural, social, and geographical differences between these countries are as great as between these countries and Western countries. If the point was 